\title{
O uso dos repositórios na visão do Designer
}

\section{Instrucional}

\author{
The use of the repositories on the view of the instructional designer
}

Juliana B. Diana

Engenharia e Gestão do Conhecimento Universidade Federal de Santa Catarina juliana.diana@ posgrad.ufsc.br

Fernando José Spanhol

Engenharia e Gestão do Conhecimento Universidade Federal de Santa Catarina fernando.spanhol@ufsc.br
Cecilia E. Giuffra P.

Engenharia e Gestão do Conhecimento Universidade Federal de Santa Catarina cecilia.giuffra@posgrad.ufsc.br

Ricardo Azambuja Silveira

Informática e Estatística

Universidade Federal de Santa Catarina ricardo.silveira@ufsc.br

\author{
Marina Keiko Nakayama \\ Engenharia e Gestão do Conhecimento \\ Universidade Federal de Santa Catarina \\ marina@egc.ufsc.br
}

\begin{abstract}
Resumo $O$ processo de produção de material didático para a Educação a Distância exige, dos profissionais envolvidos, a busca constante por ferramentas e recursos que contribuam com a criação do conteúdo. Nesse sentido, os repositórios atuam como espaços que armazenam objetos de aprendizagem e materiais didáticos previamente produzidos, para que estes sejam utilizados ou adaptados de acordo com a proposta do curso. Nesta perspectiva, a presente pesquisa objetiva apontar qual o estado atual do uso dos repositórios de Objetos de Aprendizagem na visão do Designer Instrucional. Para isto foi realizada uma pesquisa qualitativa utilizando como estratégia de investigação entrevistas semiestruturadas com a participação de seis profissionais de design instrucional. Os resultados apontaram o baixo uso dos repositórios de objetos de aprendizagem no processo de construção do material didático em cursos oferecidos na modalidade à distância, sendo percebido que essa escolha dos designers instrucionais acontece por diversas razões como: (1) pouca divulgação dos repositórios, (2) falta de conhecimento de procedimentos de busca de repositórios e (3) por considerar mais prático o processo de criação do material desde o início, além de poder elaborar um material específico para os objetivos propostos.
\end{abstract}

Palavras-Chave: Repositórios. Designer Instrucional. Objetos de Aprendizagem

\begin{abstract}
The teaching materials production process in distance education requires of its professionals the constant search for tools and resources that contribute to the creation of the content. In this sense, the repositories acts as spaces which store learning objects and teaching materials already produced to be used or adapted according to the course proposal. In this perspective, this research aims to point out which is the current state of the use of learning objects repositories in the Instructional Designer view. For this a qualitative study using semistructured research interviews as a strategy involving six professional of instructional designer was performed. The results indicated a low use of learning objects repositories in the teaching materials construction in courses offered in distance mode, and realized that the instructional designers choice happens because: (1) there is a little disclosure of repositories, (2) the lack of knowledge of procedures of search repositories and (3) because they consider the creation process of the material from the beginning more practical, in addition to the possibility of elaborate an specific material for the proposed objectives.
\end{abstract}

Keywords: Repositories. Instructional Designer. Learning Objects. 


\section{Introdução}

Na educação a distância existem diversos recursos e ferramentas que as pessoas envolvidas na criação dos materiais didáticos utilizam durante seu desenvolvimento Estes materiais, em muitos casos, são produzidos na forma de Objetos de Aprendizagem (OA) e podem ser acessados utilizando repositórios de OA.

O uso dos repositórios de OA na Educação a Distância $(\mathrm{EaD})$ deve contribuir para a reutilização efetiva de objetos e materiais existentes, diminuindo assim a duplicação do trabalho realizado pelos professores conteudistas, designers instrucionais (DI), diagramadores, revisores, e outros profissionais que participam na criação e produção dos conteúdos.

Para conhecer um pouco mais do trabalho dos DIs, no que se refere à exploração dos repositórios de $\mathrm{OA}$ e para identificar a frequência do uso destes repositórios na criação de material didático para conteúdo online, foi realizada a presente pesquisa que busca responder à seguinte pergunta: Qual é o real uso dos repositórios por parte dos designers instrucionais, durante a construção do material didático em EaD?

Dessa forma, o objetivo geral deste artigo é apontar o uso atual dos repositórios de OA, por parte do DI. Para tanto se deve apontar o conhecimento do DI em relação aos repositórios de OA, apresentando como são usados os objetos de aprendizagem disponíveis nos repositórios, durante o processo de produção de material, e identificando a necessidade do uso destes repositórios.

\section{Repositórios de Objetos de Aprendizagem}

Um repositório, segundo o Novo Dicionário Aurélio da Língua Portuguesa [1], é um "lugar próprio para guardar alguma coisa; depósito. Repertório, coleção”. Existem diferentes tipos de materiais que podem ser armazenados nestes repositórios, que podem ser físicos ou digitais. Na educação os repositórios são destinados ao armazenamento de Objetos de Aprendizagem (OA) e definidos como material educacional que pode ser digital ou analógico, sendo que este pode ser usado, reutilizado e referenciado no processo de ensinoaprendizagem apoiado pela tecnologia [12].

Quando os objetos a serem armazenados são digitais, os repositórios tomam o nome de repositórios digitais, e são definidos como "coleções de informação digital, que podem ser construídas de diferentes formas e com diferentes propósitos" [14] (p. 1). Assim, um repositório digital pode conter documentos ou qualquer outro tipo de arquivo digital, como um objeto de aprendizagem, por exemplo, e pode ser utilizado de forma institucional em universidades ou empresas ou, também, de forma pessoal.

Os objetos disponibilizados em repositórios são organizados utilizando os metadados, que são algumas características relevantes dos documentos e objetos, informadas ao momento de fazer o cadastro destes no repositório, sendo depois utilizadas para a recuperação dos materiais, por meio de sistemas de busca [23].

Os repositórios de OA são utilizados para compartilhar recursos didáticos disponíveis na internet. Existem dois tipos principais de repositórios, aqueles que contêm os objetos e seus metadados, e aqueles que contêm só os metadados. Neste caso os objetos se encontram em um local remoto e o repositório é usado como uma ferramenta para localizá-los [7].

Para Silva [21], os repositórios de OA devem ser organizados levando em conta "a realidade da comunidade de professores e educadores, estabelecendo o diálogo entre o repositório e seus usuários" (p. 102). Além disso, a autora ressalta a importância da padronização na descrição, pois isso favorece o compartilhamento e reusabilidade.

Entre os repositórios mais conhecidos, fora do Brasil, está o Merlot, repositório centralizado que fornece um serviço de revisão por pares, oferecido por comunidades de pessoas que possuem experiência em diferentes áreas do conhecimento, e o CAREO, coleção de OA centralizada destinada aos educadores no Canadá [7].

Entre os repositórios de objetos de aprendizagem no Brasil podemos considerar:

- RIVED - Rede Interativa Virtual de Educação MEC: Programa da Secretaria de Educação a Distância (SEED) que produz e disponibiliza objetos de aprendizagem, com o objetivo de melhorar a aprendizagem na educação básica e a formação cidadã do aluno [4].

- LUME - Repositório digital da Universidade Federal do Rio Grande do Sul (UFRGS): É um portal que contêm as coleções digitais produzidas na Universidade, além de outros documentos que a UFRGS considera que são interessantes para serem divulgados e tem como objetivo a reunião, preservação e divulgação de garantia de acesso confiável e permanente aos documentos disponíveis. [26].

- CESTA - Coletânea de Entidades de Suporte ao uso de Tecnologia na Aprendizagem: Projeto da UFRGS que tem como objetivo sistematizar e organizar os registros dos objetos educacionais desenvolvidos pela equipe do programa de pósgraduação em Informática na Educação e do Centro Interdisciplinar de Novas Tecnologias na Educação (CINTED) da Universidade, para cursos de capacitação em Gerência de Redes, Videoconferência e Pós-Graduação Lato-sensu em Informática na Educação [25]. 
- Banco Internacional de Objetos Educacionais Desenvolvido pelo MEC em parceria com o Ministério da Ciência e Tecnologia, este repositório tem o objetivo de compartilhar recursos educacionais digitais de livre acesso em diversos formatos e níveis de ensino. Este repositório está integrado ao Portal do Professor, também desenvolvido pelo MEC [2].

Repositórios de objetos de aprendizagem podem ser utilizados por profissionais que fazem parte do processo de criação do material didático em diversos cursos, como os de Educação a Distância, que contam com Designers Instrucionais que convertem o conteúdo em material impresso ou online.

\section{Designer Instrucional}

Designer instrucional (DI) é o profissional atuante na EaD e desenvolve um papel de extrema importância no curso. As características da $\mathrm{EaD}$ envolvem principalmente a distância física e geográfica entre professor e aluno na qual o processo de ensino e aprendizagem ocorre através da utilização de meios e tecnologias de informação e comunicação [3] e, por conta dessa particularidade, a oferta do material didático disponibilizado ao aluno deve apresentar características que contribuam com sua aprendizagem, mesmo não estando face-a-face com o professor.

Os primeiros registros relacionados ao trabalho deste profissional fazem referência à Segunda Guerra Mundial quando profissionais de diversas áreas de atuação eram convocados com o objetivo de preparar material a fim de instruir recrutas sobre assuntos técnicos e, dessa forma, no período de 1950 a 1970 iniciaram as discussões sobre a elaboração e organização de materiais com propósito de ensinar [20].

No Brasil, a regulamentação da profissão aconteceu em 30 de dezembro de 2008, quando o Ministério do Trabalho e Emprego a reconheceu através da Norma Regulamentadora 2394-35 nomeando o Designer Instrucional como "Desenhista Instrucional", "Desenhista Educacional" ou "Projetista Instrucional" [5]. Dessa forma, observa-se que não existe consenso quanto ao termo que seja correto ou mais apropriado.

Com o passar do tempo a função do designer instrucional foi ganhando cada vez mais definições e, com a crescente demanda de cursos de EaD, esse profissional passou a desempenhar um papel importante, principalmente quando relacionado à produção do material didático.

$\mathrm{Na}$ EaD o aluno precisa se sentir motivado e ter a possibilidade de interagir com material a fim de contribuir com a própria aprendizagem [19] e, nesse sentido o DI desempenha o seu papel, mediando a ação institucional e sistemática de ensino, que tem início no planejamento, passando pelo desenvolvimento e utilização de métodos, técnicas, atividades, materiais e produtos educacionais em situações didáticas, para que assim promova a aprendizagem humana [8].

Nitzke et al. [16] aponta o DI como o profissional responsável por gerenciar o processo de construção de materiais educacionais digitais fazendo a união entre os objetivos propostos pelo curso com o conteúdo do material. Schuelter [18] ainda complementa que o DI realiza uma ação que envolve diversas etapas no projeto do curso.

Para apresentar um resultado que motive o aluno à aprendizagem, o trabalho do DI envolve atenção e cuidados especiais, principalmente quando o material produzido for destinado a cursos na modalidade a distância [19]. Filatro e Piconez [9] apontam a atividade desenvolvida pelo DI como uma ação sistemática de planejamento e implementação de novas estratégias didáticas e metodologias de ensinoaprendizagem. Nesse sentido França [10] complementa apontando que para realizar essas atividades o DI deve possuir conhecimento de teorias e práticas pedagógicas e fazer uso das mídias e tecnologias, devendo manterse atualizado quanto às novas linguagens, para estabelecer relações significativas com a concepção do curso.

A ação do DI está pautada na elaboração de materiais que favoreçam o estudo autônomo e a distância, promovendo assim a utilização de componentes mediadores da aprendizagem, como as Tecnologias de Informação e Comunicação (TIC) [15] e para que isso aconteça com maior eficácia o DI deve ter o domínio das diversas informações que envolvam o curso, incluindo o perfil dos alunos que utilizarão o material e as expectativas que os mesmos possuem e, a partir daí realizar a escolha da metodologia, dos materiais e das mídias, passando pelo acompanhamento da aprendizagem até a avaliação final [20].

Filatro e Piconez [9] apontam que na EaD o DI se dedica ao planejamento, projeto, produção e publicação de textos, imagens, gráficos, sons, simulações, atividades e tarefas ancoradas em suportes virtuais. Mülbert e Matuzawa [15] vêm de encontro e complementam afirmando a participação ativa do DI em todo o processo do curso através da interação com coordenação, professores conteudistas, designer visual e gráfico e revisor ortográfico.

Os diferentes momentos em que o DI está envolvido no projeto educacional têm cinco fases que estão interligadas e acontecem de forma ordenada, sendo elas: Análise, Design, Desenvolvimento, Implementação e Avaliação. Definido como modelo ADDIE, essas etapas acontecem de uma forma ordenada na qual se complementam, conforme apresentado na figura 1 . 


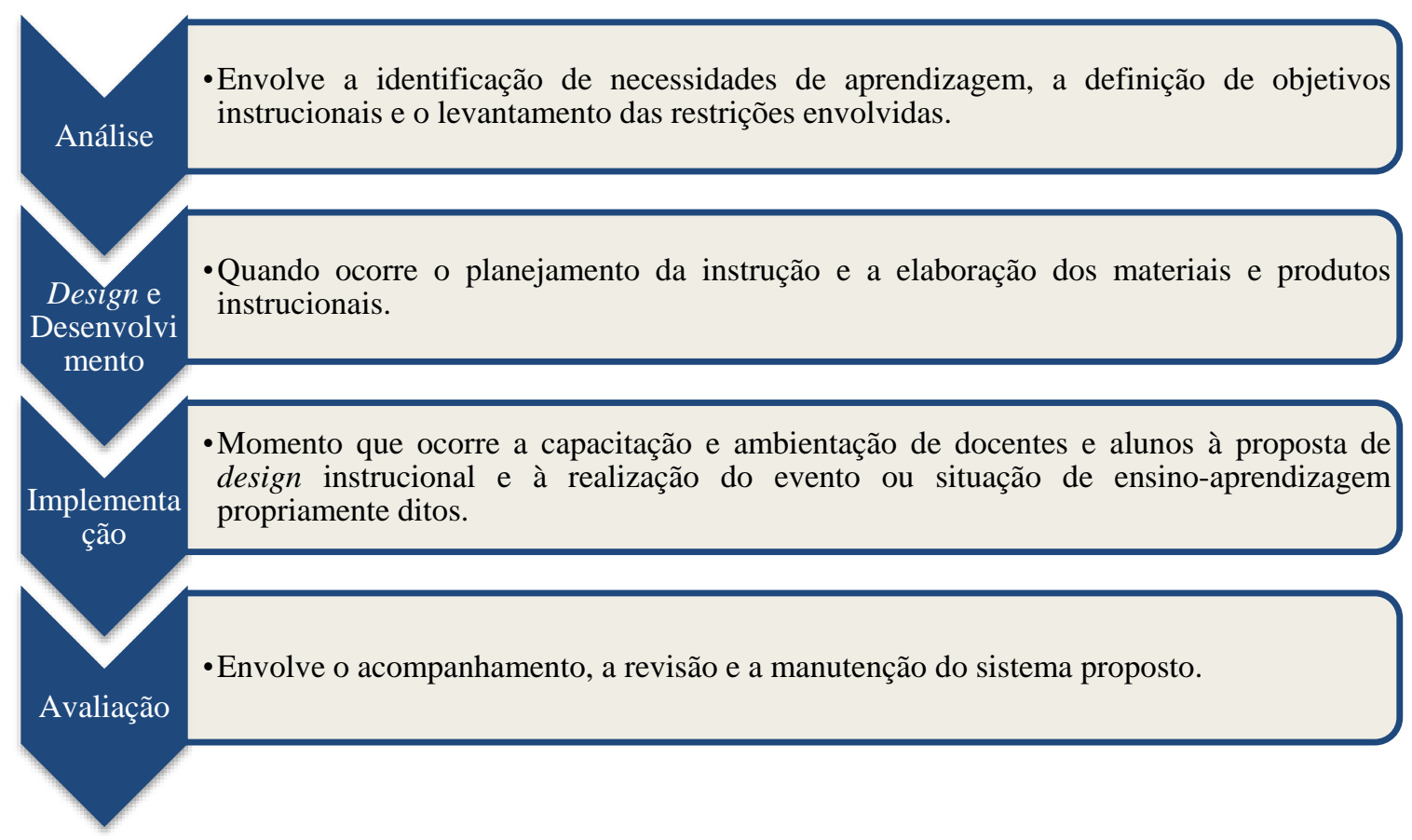

Figura 1: Fases do processo de design instrucional Fonte: Adaptado de Filatro e Piconez [9].

Considerando as características e etapas apresentadas em relação ao trabalho desenvolvido pelo Designer Instrucional, vale ressaltar que é necessário que este profissional possua conhecimento em diversas áreas, passando assim a compor uma equipe multidisciplinar para a realização de uma atividade de ação interdisciplinar, para que dessa forma contribua em projetos que estejam voltados para a construção do conhecimento [20].

\section{Trabalhos relacionados}

A fim de identificar pesquisas que abordam a relação entre o uso dos repositórios pelos DIs. Foi realizada uma busca pelos termos em português utilizando os termos "repositórios" and "design instrucional" e outra utilizando "repositórios" and "educação a distância". Também foi realizada uma pesquisa na base de dados Scopus utilizando os termos "repository" and "instrucional design", limitando o tempo de busca aos últimos dez anos.

Após as buscas realizadas foram encontrados 12 artigos relacionados com os termos de pesquisa. Foram definidos dois critérios de seleção para a inclusão deles nesta seção: a relevância do título do artigo e o conteúdo do resumo. Feita a análise dos títulos e resumos, percebeu-se que as pesquisas abordam o tema sob diferentes olhares, no qual relacionam os designers instrucionais e repositórios, porém, não se encontraram pesquisas sobre o uso atual dos repositórios na produção de material para cursos a distância, realizados pelos designers instrucionais, objeto de estudo deste trabalho.
Os trabalhos que apontam o uso de repositórios de objetos de aprendizagem mostram que o uso dos repositórios não é amplamente divulgado e, por esta razão, o uso dos recursos disponíveis neles é limitado. Além disso, estes trabalhos apresentam a importância dos repositórios institucionais na educação a distância.

Analisando os trabalhos encontrados tem-se que Gomes [27] relata o uso gratuito dos repositórios e afirma que não há a divulgação suficiente para os profissionais que poderiam explorar os recursos destes espaços para complementar o conteúdo da aula. Para a autora (p. 10) "através de OA é possível aumentar o interesse do usuário pelo tema que está sendo abordado no conteúdo do recurso digital, assim como participá-lo das ações para que esse se envolva mais e tenha maior interação". Sob outro ponto de vista, Diniz [6] (p. 125), aponta que "Os repositórios institucionais são importantes no auxílio à Educação e Ensino a Distância (EAD), pois evidenciam a qualidade do ensino a distância maximizando a aprendizagem”. Estes repositórios, além de armazenar objetos de aprendizagem, contribuem na gestão do conhecimento científico que é gerado nas instituições, o que inclui artigos e trabalhos de pesquisa, que também podem ser usados pelos designers instrucionais como material complementar.

A partir dessas considerações, percebe-se a lacuna existente em pesquisas sobre o uso dos repositórios na visão do DI, considerado, como visto anteriormente, um dos principais atores na construção de material didático. 


\section{Protocolo de pesquisa}

Foi realizada uma pesquisa qualitativa como meio de explorar e entender o significado que os indivíduos possuem em relação a uma questão social. Dessa forma, esta pesquisa se classifica como exploratória visto que seu objetivo está relacionado a explicitar um determinado problema (uso de repositórios) e, como forma de atingir tal objetivo envolve entrevistas com pessoas (DIs) que possuem experiência na questão do problema apresentado [11].

Os participantes da pesquisa são Designers Instrucionais que atuam no processo de elaboração do material didático a ser utilizado em cursos oferecidos na modalidade a distância.

A escolha dos participantes aconteceu inicialmente através de uma pesquisa nos sites dos cursos oferecidos a distância da Universidade Federal de Santa Catarina (UFSC) e em empresas que desenvolvem esse tipo de serviço. Após a seleção prévia dos possíveis participantes foi realizado contato via e-mail com uma breve apresentação e justificativa do contato e da pesquisa. Após o retorno das pessoas contatadas, com a aceitação e disponibilidade em participar da pesquisa, foram agendados o horário e o local para a realização da entrevista.

A pesquisa sobre o uso dos repositórios teve o intuito de conhecer mais sobre o trabalho do profissional de design instrucional e o uso que ele e os professores criadores de conteúdo fazem dos repositórios para a elaboração do material didático de cursos a distância.

Para isso foram formuladas questões norteadoras que buscavam identificar quais recursos e/ou ferramentas são mais utilizadas na criação dos materiais didáticos e como é feita essa escolha. Os entrevistados também foram questionados sobre o papel do professor no processo de criação do material e em relação ao uso dos repositórios de OA por parte do mesmo. Com foco no uso dos repositórios, questionouse sobre o aproveitamento ou não dos materiais disponíveis, além de conhecer os critérios para escolha dos repositórios. Para finalizar questionou-se sobre o processo de criação dos objetos.

\section{Resultados}

Ao iniciar a entrevista foi feita uma explanação do contexto do trabalho e, quando necessário, o esclarecimento de dúvidas. Foi solicitada autorização para gravação do áudio de todas as entrevistadas e em seguida foi entregue o Termo de Consentimento Livre e Esclarecido a fim de esclarecer os objetivos da pesquisa bem como preservar a identidade das participantes.

Foram realizadas seis entrevistas. Cinco entrevistas foram realizadas em diversos espaços e uma realizada via Skype, sendo que todas as entrevistas foram transcritas integralmente, para aprimorar a capacidade de análise. Uma característica particular das pessoas entrevistadas foi que todas eram do sexo feminino e, para preservar a identidade das participantes foram adotados nomes fictícios. Como todas as entrevistadas foram mulheres os nomes fictícios escolhidos foram nomes de flores.

As entrevistadas possuem experiência como DI entre dois anos e meio e nove anos, sendo que a média de anos de experiência das seis participantes é de cinco anos e meio.

A partir das questões norteadoras foram obtidas informações das participantes no que se refere ao uso dos repositórios e objetos de aprendizagem, principalmente em cursos de Educação a Distância com materiais online. Estas informações são expostas a seguir.

Para a criação de material didático, incluindo a criação dos objetos de aprendizagem e o acesso aos repositórios para a seleção destes objetos há a necessidade de se ter uma "equipe multidisciplinar que desenvolva uma constante discussão sobre a linguagem e os recursos que serão adequados ao projeto pedagógico e ao público que fará uso desse recurso na Internet" [22] (p. 1333).

O início do processo de criação do material didático na forma de objeto de aprendizagem acontece com a elaboração do conteúdo a ser inserido nele que, inicialmente, deve ser elaborado pelo conteudista e, depois, deve ser enviado para o DI.

Nesta pesquisa, ao serem questionadas sobre o uso de repositórios pelos conteudistas, Jasmim afirmou que o uso do repositório é muito baixo tanto pelo professor quanto pela equipe que integra o processo de construção do material. Para Amarilis em nenhum momento os professores conteudistas utilizam repositórios, seja de texto ou de imagem. A esse respeito, Camélia faz uma importante fala sobre o uso de repositórios pelos professores conteudistas, pois sabendo que não são utilizados ela, como DI, busca incentivar o uso dos repositórios e aponta: "Eu tenho tentado passar isso para eles assim, tentar selecionar melhor as fontes onde eles pesquisam, lembrar que existem os repositórios, lembrar que existem as bases de dados, lembrar que eles tem $\mathrm{n}$ tipos de páginas para poder resgatar esses materiais", porém afirma que as respostas em sua maioria são negativas.

Em controvérsia Iris apontou que o Ambiente Virtual de Aprendizagem (AVA) é frequentemente utilizado como um local de busca de material já produzido e compartilhado anteriormente por outros professores. A esse respeito, Tarouco e Schmitt [23] apontam que embora o AVA possua materiais didáticos e OA organizados como forma de arquivamento interno de um curso ou disciplina, também é possível implantar um sistema de suporte à gestão de conteúdo 
educacional através de um serviço específico de Repositórios de Objetos de Aprendizagem que facilitam e contribuem com o armazenamento e gestão de uso e reuso destes materiais.

Iris ainda complementou afirmando que durante o processo de desenvolvimento do material são feitas buscas de imagens em repositórios de domínio público por conta de direitos autorais, ou ainda através da permissão de licença de uso concedido previamente. Nesse sentido vale notar que nos repositórios institucionais a propriedade intelectual e os direitos autorais são protegidos na possibilidade de licença concedida, obedecendo as normas de autoria diferenciada e com diferentes amplitudes para o atendimento de variados padrões de reserva de direitos [17].

$\mathrm{Na}$ experiência de Jasmim nem sempre os repositórios de imagens são utilizados uma vez que pode ser solicitada no projeto a criação de novas imagens ou ainda de imagens personalizadas de acordo com a proposta do curso, fazendo muitas vezes que o repositório seja descartado e um novo material seja criado.

Para Begônia a indisponibilidade de repositórios pode ser um fator a se considerar e, buscando solucionar essa questão a equipe está na etapa de construção de um repositório próprio para que todos possam ter acesso ao material já produzido de forma centralizada, e ainda complementa afirmando que "tem bastante material do ambiente virtual, só que tem isso em cada disciplina, tem repositório onde os professores podem ver tudo que foi produzido na disciplina", o que também foi afirmado por Camélia, apontando que a centralização do material ao invés do fracionamento em disciplinas contribui com o acesso aos materiais já produzidos.

Tomaél e Silva [24] apontam que programas e ações de incentivo para criação de repositórios institucionais vêm crescendo no Brasil, onde novas formas de compartilhamento da informação são apresentadas a fim de modificar os padrões de disseminação e acesso aos materiais já produzidos. Além disso, a criação dos repositórios institucionais atua como uma ferramenta que "torna visível a produção intelectual de professores e alunos das universidades" [24] (p. 3). Rosa et al [17] complementa apontando que a participação da comunidade científica no processo de disponibilização do repositório institucional deve acontecer de forma com que todos estejam cientes dos resultados proporcionados, dessa forma pode-se dizer que estará contribuindo principalmente com a disseminação e compartilhamento de material e de conhecimento.

Quando questionadas sobre a negativa em relação ao uso dos repositórios foi possível notar que muitos consideram mais fácil criar desde o início, pois como aponta Violeta, "a partir do momento que o professor não sabe o que buscar, onde buscar, como buscar, essa busca acaba levando muito mais tempo, sendo muito mais difícil do que criar uma coisa sofisticada sobre aquilo", e dessa forma interfere no tempo para a produção do material.

Existem diversos critérios para selecionar material de repositórios ou da web que pode ser aproveitado em algum curso. Para Souza e Silva [22] esta escolha de material deve ser realizada com base em "concepções pedagógicas que mobilizem os processos de desenvolvimento de aprendizagem dos alunos" (p. 1331). Com isto, entende-se que a preocupação na escolha do material está relacionada diretamente com o aprendizado do aluno, tentando também oferecer para ele uma melhor experiência de aprendizagem.

Outro critério utilizado na escolha dos objetos, segundo Camélia, é a necessidade que a equipe tem para desenvolver uma atividade específica. Assim, a equipe procura aquilo que atende à necessidade dela, realizando testes em diversos objetos e selecionando aquele que consideram melhor, levando em conta também a interação dos objetos, pois quanto mais interativo ele é mais atrativo para os alunos.

Além disso, Camélia comenta que a complexidade ou simplicidade de um objeto não é algo que interfira na decisão de utilizar ou não determinado objeto, pois às vezes o fato de ser complexo faz com que ele tenha mais coisas das que são necessárias e nem sempre isso é algo positivo.

Outro critério de escolha mencionado é a confiança nos repositórios e páginas usadas na web, tendo preferência por aquelas oficiais do MEC ou de Universidades, no entanto, se houver algum objeto de aprendizagem que possa ser útil disponível em alguma página na web, um blog, por exemplo, este não é totalmente descartado e a equipe se preocupa em verificar se o blog se dedica ao ensino de forma profissional e, depois de confirmar isso, conseguem utilizar o objeto.

No que se refere ao reuso dos objetos de aprendizagem, para Souza e Silva [22] a equipe deve saber "trabalhar com a diversidade, para que, cada vez mais, amplie-se o processo de interação entre os que criam e os que utilizam os OA" (p. 1344).

Na visão de Jasmim, atualmente, pelo fato de não se ter o costume de procurar materiais dos repositórios e reutilizá-los, um professor pode produzir um módulo para $\mathrm{EaD}$ e depois um outro professor pode produzir um material muito similar. Sendo que poderia acontecer da equipe multidisciplinar entrar em contato com o primeiro professor e pedir uma atualização do material para que o trabalho não seja duplicado.

Contudo, nem sempre existe a necessidade de procurar materiais prontos, pois na construção de alguns materiais didáticos novos tudo é produzido desde o inicio, indo de acordo com o que o professor 
solicita e, ainda na experiência de Jasmim, há quem considera que com o uso de materiais já utilizados em outros projetos pode ficar tudo muito semelhante. Por isto, nesses casos, existe um reuso muito baixo de objetos e os professores criam os materiais.

Além disso, a entrevistada ainda aponta que, dependendo o trabalho, são utilizados sites (repositórios) de imagens. Neste caso o reuso é feito inserindo as imagens prontas em materiais que estão sendo criados do zero. Já na experiência da Begônia, os repositórios são utilizados, basicamente, para pegar documentos e vídeos e não para obter objetos de aprendizagem.

Por outro lado, segundo Iris, o aproveitamento de conteúdo ou de objetos de um curso para outro não existe e isso acontece, principalmente, porque é feita só uma edição do curso e não precisaria fazer novamente o material. No entanto, em uma segunda edição do curso a necessidade de usar coisas da primeira edição viria a aumentar.

Ainda nessa linha de reuso dos objetos, o conceito de reutilização dos OA faz parte do dia a dia das Designers, que conseguem visualizar a utilidade de um repositório e por isto, como foi comentado anteriormente, algumas das entrevistadas falaram sobre um espaço que está sendo criado no repositório da UFSC para o curso em que atuam. Begônia acredita que isso ajudaria a explorar mais o reuso dos materiais, que na maioria dos casos, geram bastante trabalho para serem criados e muitas vezes são usados em um lugar só, resultando materiais pouco eficientes.

Segundo Macedo [13] "a adoção de padrões globais na criação, indexação, e tecnologia de objetos de aprendizagem é crucial para assegurar a reutilização e interoperabilidade e qualidade dos objetos de aprendizagem." (p. 100). Para o autor os OA precisam ter uma padronização na hora de inseri-los nos repositórios, para que a localização deles seja mais efetiva.

Quando os objetos são recuperados dos repositórios eles podem ser alterados, modificados ou atualizados, no entanto, conforme experiência de Camélia, "o pequeno uso que se faz dos repositórios é mais para pegar os objetos prontos", e geralmente não é feita uma adaptação dos objetos. Eles os pegam como estão no repositório e usam, para poupar tempo e também pela praticidade. Além disso, entre os repositórios utilizados, o do MEC é mais explorado pela equipe de produção, mas não pelos professores. Camélia acredita que isso acontece porque os professores não têm conhecimento da existência dele.

Já os materiais criados pela equipe são reusados fazendo alterações só quando precisam ser atualizados, por exemplo, a equipe que trabalha junto com a Camélia usa uma tabela de fonética de uma Universidade fora do Brasil que foi adaptada para o
Português, mas no geral usa os objetos prontos e quando precisa criar material a equipe cria, levando em conta alguns exemplos ou fazendo uma criação própria. Esta criação acontece no caso de ter uma equipe mais completa, pois precisa de profissionais como animador, ilustrador, entre outros, que facilitam o processo. Caso contrário, é mais usual procurar material na internet.

\section{Considerações finais}

O objetivo deste artigo foi apontar o estado atual no uso dos repositórios de OA, por parte do DI. Dessa forma, aponta-se o conhecimento do DI em relação à existência dos repositórios de OA, além do uso que eles fazem destes objetos disponíveis nos repositórios, durante o processo de produção de material. E, também, identifica-se a necessidade do uso de repositórios de $\mathrm{OA}$.

$\mathrm{Na}$ afirmação de Diniz [6], "repositórios podem servir como imensa base de dados para os professores (...) divulgarem suas produções à comunidade acadêmica; inserir-se em grupos de pesquisa, compartilhar informações" (p. 131), o que é positivo para a comunidade científica. Da mesma forma, para Gomes [27] "os repositórios de OA são importantes, pois armazenam em um único ambiente variados exemplos de recursos educacionais que podem ser utilizados" (p. 10). A autora ainda afirma que "existem muitos OAs em variados repositórios na internet e que estes podem ser usados com maior periodicidade pelos docentes" (p. 10).

Tomando por base as considerações obtidas na análise das entrevistas e na leitura dos tópicos abordados nos artigos encontrados, conclui-se que o uso de repositórios de OA existe, porém, não acontece com frequência e que o mais comum é criar novos materiais, principalmente para cursos online. Em alguns casos, o fato de criar o material desde o início é mais atrativo pela necessidade de algumas instituições de ter materiais inéditos, no entanto, alguns OAs são retirados dos repositórios e são feitas as adaptações, quando necessárias, para que o objetivo e a proposta do curso sejam atendidos.

Além disso, o uso de repositórios é pouco difundido e isto dificulta a exploração destes espaços pelos professores e demais participantes do processo de criação de material no geral, como são os DI. E, para aumentar a frequência no uso de materiais disponíveis nos repositórios, a criação de um repositório institucional seria uma ação que viria a contribuir com o compartilhamento do material já produzido anteriormente. Complementando esta conclusão temos o pensamento de Diniz [6], que afirma que os repositórios institucionais facilitam o acesso e a disseminação da informação científica tendo diversos materiais em um único lugar, "contribuindo para a projeção de toda a produção científica da instituição, permitindo maior visibilidade dessa produção e 
favorecendo os avanços científicos do país no qual a instituição está inserida" (p. 132).

Outro ponto que foi percebido nas entrevistas foi o desconhecimento, em alguns casos, do que é um objeto de aprendizagem em si, além disso, o conceito de repositório também não estava claro para todas as entrevistadas que veem o ambiente virtual de aprendizagem e bibliotecas online como um repositório. Dessa forma, percebeu-se que não existe preconceito quanto ao uso de repositórios, no entanto, o baixo uso destes acontece pelo fato de haver pouca divulgação de repositórios, bem como pela falta de conhecimento acerca dos procedimentos de busca, considerando que este fator atrasa o processo de criação, o que faz com que os criadores de conteúdo recorram a cursos já realizados e com material disponibilizado dentro do AVA, além da possibilidade de elaborar um material específico para os objetivos propostos, colaborando assim com a compreensão acerca do tema.

No geral, podemos concluir que o uso dos repositórios, mesmo não sendo muito comum por não ser amplamente difundido, contribui no processo de criação de material, utilizando, reutilizando e atualizando materiais previamente desenvolvidos, no entanto, esta contribuição só é possível a partir do momento que se tem o conhecimento suficiente para explorar as vantagens que ele oferece da melhor forma. Para isso, é importante que os materiais e/ou objetos de aprendizagem sejam organizados dentro do repositório, de forma que facilite a busca e recuperação deles por parte dos usuários, não causando dúvidas e promovendo o uso dos repositórios. Pois, é provável que um professor que sente dificuldade em acessar um repositório ou em encontrar algum material, não sinta segurança em utilizar esta ferramenta novamente. E este é o comportamento que se procura evitar.

\section{Referências}

[1] Aurélio. Novo Dicionário da Língua Portuguesa. $3^{\mathrm{a}}$ edição. Editora Positivo. Versão Online. 2004

[2] C. E. Bielschowsky; C. L. Prata. Portal Educacional do Professor do Brasil. Revista de Educación, n. 352. mayo-agosto 2010

[3] Brasil. Ministério da Educação. Decreto n. 5.622, de 19 de dezembro de 2005. Regulamenta o art. 80 da Lei n. 9.394, de 20 de dezembro de 1996, que estabelece as diretrizes e bases da educação nacional.

$$
\text { Disponível }
$$

em: <http://www.planalto.gov.br/ccivil 03/_Ato20042006/2005/Decreto/D5622.htm\#art37>

[4] Brasil. Ministério da Educação. Rived. Disponível em: 〈http://rived.mec.gov.br/site_objeto_lis.php〉.

[5] Brasil. Ministério do Trabalho e Emprego. Norma Regulamentadora 2394-35, de 30 de Dezembro de
2008. Classificação Brasileira de Ocupações. Disponível em: <http://www.mtecbo.gov.br/cbosite/pages/pesquisa s/BuscaPorTituloResultado.jsf $>$.

[6] A. S. S. Diniz; A. S. Sousa. O potencial dos repositórios institucionais na educação a distância. Revista UNI. v. 1, p. 125-133, 2011.

[7] S. Downes. Design and reusability of learning objects in an academic context: a new economy of education? In.: USDLA Journal. v.17, n.1 online Janeiro. 2003. Disponível em: <http://www.downes.ca/post/31468>.

[8] A. Filatro. Design Instrucional contextualizado: educação e tecnologia. São Paulo: Senac. 2004.

[9] A. Filatro; S. C. B. Piconez. Design instrucional contextualizado. In.: $11^{\circ}$ Congresso Internacional de Educação a Distância, 7 a 10 de setembro de 2004.

[10]G. França. O Design instrucional na Educação a Distância. São Paulo: Esfera, 2007.

[11]A. C. Gil. Como elaborar projetos de pesquisa. 4 ed. São Paulo: Atlas, 2002.

[12] IEEE-LTSC. WG12: Learning Object Metadata. IEEE Learning Technology Standards Committee, $2005 . \quad$ Disponível em: $<$ http://ltsc.ieee.org/wg12/>.

[13]C. M. S. Macedo. Diretrizes para criação de objetos de aprendizagem acessíveis. Tese (Doutorado em Engenharia e Gestão do Conhecimento), Universidade Federal de Santa Catarina, Florianópolis, SC, 2010.

[14]A. Martins; M. B. Nunes; E. Rodrigues. Repositórios de informação e ambientes de aprendizagem: Criação de espaços virtuais para a promoção da literacia e da responsabilidade social. Rede de Bibliotecas Escolares Newsletter. n. ${ }^{\mathbf{o}} 3$. 2008. Disponível em: <http://www.rbe.minedu.pt/news/newsletter3/newsleter_n3_ficheiros/pa ge0016.htm>.

[15] A. L. Mülbert; F. L. Matuzawa. La transformación del proceso de diseño instrucional: del impreso a la multimedia. RIED, v.14: 1, 2011, p. 41-54.

[16] J. A. Nitzke.; M. L. F. Carneiro; P. C. S. J. Passos. Gestão do desenvolvimento de objetos de aprendizagem digitais. In: Sexta Conferencia Latinoamericana de Objetos de Aprendizaje y Tecnologia de la Educación - LACLO 2011, 2011, Montevideo. Anais da 6ta. Conferencia Latinoamericana de Objetos de Aprendizaje y Tecnologías para la Educación. LACLO 2011. Montevideo: Universidad de La Republica, 2011. v. 1.p. 111-120.

[17]F. Rosa; R. F. Meirelles; M. Palacios. Repositório institucional da Universidade Federal da Bahia: implantação e acompanhamento. Inf. \& Soc.: Est., João Pessoa, v.21, n.1, p. 129-141, jan./abr. 2011.

[18]G. Schuelter. Modelo de educação a distância empregando ferramentas e técnicas de gestão do conhecimento. 2010. 262 p. Tese (Doutorado em Engenharia e Gestão do Conhecimento) - 
Universidade Federal de Santa Catarina, Florianópolis, SC, 2010.

[19]A. R. L. Silva; L. P. S. Castro. A relevância do design instrucional na elaboração de material didático impresso para cursos de graduação a distância. Revista Intersaberes, Curitiba, v. 4, n. 8, p. 136-149, jul/dez 2009.

[20]A. R. L. Silva. Diretrizes de design instrucional para elaboração de material didático em EaD: uma abordagem centrada na construção do conhecimento. Dissertação (Mestrado em Engenharia e Gestão do Conhecimento), Universidade Federal de Santa Catarina, Florianópolis, SC, 2013.

[21]E. Silva; L. Café; A. Catapan. Os objetos educacionais, os metadados e os repositórios na sociedade da informação. Ciência da Informação, Brasília, DF, Brasil, 39, ago. 2011. Disponível em: http://revista.ibict.br/cienciadainformacao/index.ph p/ciinf/article/view/1805/1382.

[22] K. P. Souza; B. D. Silva. Caminhos percorridos na construção de objetos de aprendizagem: um estudo de caso. Em: II Congresso Internacional TIC e Educação. 2012

[23]L. Tarouco; M. Schmitt. Adaptação de metadados para Repositórios de Objetos de Aprendizagem. Renote, v. 8, n. 2, 2010. Disponível em: <http://seer.ufrgs.br/renote/article/view/15225/898 $8>$.

[24]M. I. Tomaél; T. E. Silva. Repositórios institucionais: diretrizes para políticas de informação. VIII Encontro Nacional de Pesquisa em Ciências da Informação. 28 a 31 de outubro de 2007. Salvador, BA. 2007.

[25]UFRGS. CESTA. Disponível em <http://www.cinted.ufrgs.br/CESTA/>. 2013a.

[26]UFRGS. LUME. Disponível em <http://www.lume.ufrgs.br/>. 2013b.

[27]F. M. Gomes. O Uso de Objetos de Aprendizagem na Educação: Recursos Digitais Interativos em Repositórios Gratuitos. In: Simpósio Internacional de Educação a Distância - Encontro de Pesquisadores em Educação a Distância SIED: EnPED:2014, 2014, São Carlos. Anais do SIED: EnPED:2014, 2014. 